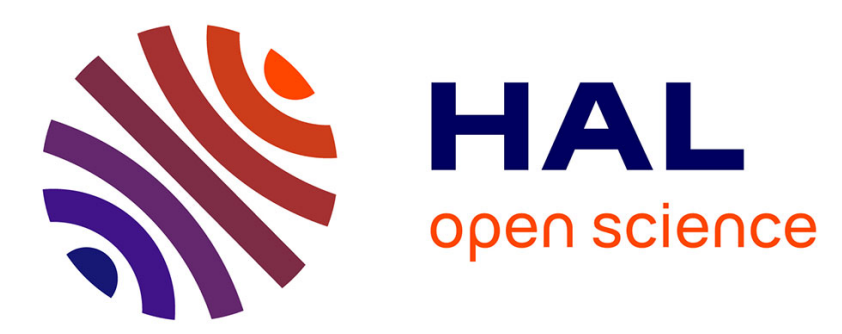

\title{
Variability of the African convection centre as viewed by outgoing longwave radiation records and relationships with sea-surface temperature patterns \\ Vincent Moron
}

\section{- To cite this version:}

Vincent Moron. Variability of the African convection centre as viewed by outgoing longwave radiation records and relationships with sea-surface temperature patterns. International Journal of Climatology, 1995, 15 (1), pp.25-34. 10.1002/joc.3370150105 . hal-01520118

\author{
HAL Id: hal-01520118 \\ https://hal.science/hal-01520118
}

Submitted on 9 Jul 2020

HAL is a multi-disciplinary open access archive for the deposit and dissemination of scientific research documents, whether they are published or not. The documents may come from teaching and research institutions in France or abroad, or from public or private research centers.
L'archive ouverte pluridisciplinaire HAL, est destinée au dépôt et à la diffusion de documents scientifiques de niveau recherche, publiés ou non, émanant des établissements d'enseignement et de recherche français ou étrangers, des laboratoires publics ou privés. 


\title{
VARIABILITY OF THE AFRICAN CONVECTION CENTRE AS VIEWED BY OUTGOING LONGWAVE RADIATION RECORDS AND RELATIONSHIPS WITH SEA-SURFACE TEMPERATURE PATTERNS
}

\author{
VINCENT MORON \\ Centre de Recherches de Climatologie Tropicale, Université de Bourgogne, BP 13821004 Dijon cedex, France
}

Received 6 August 1993

Accepted 1 March 1994

\begin{abstract}
The main African convection centre (ACC) is delimited by the $5^{\circ}$-square areas with outgoing longwave radiation less than $235 \mathrm{~W} \mathrm{~m}^{-2}$ in the domain $17.5^{\circ} \mathrm{N}-17.5^{\circ} \mathrm{S}$ and $18^{\circ} \mathrm{W}-46^{\circ} \mathrm{E}$. Four parameters (latitude and longitude of the centre of gravity, mean intensity, and extension) were analysed during the period June 1974 to December 1991. The relationships between the variability of the ACC and the main sea-surface temperature (SST) patterns were then studied. Correlation and composite analyses demonstrate that the first principal component of SST, representing mainly the variability of the eastern and the central tropical Pacific, is associated strongly with the extension and the mean intensity of the ACC. Both are strongest when cold conditions prevail in the eastern and central Pacific (= La Niña event) and smallest when warm conditions occur in the eastern and central Pacific ( = El Niño event). This relationship is strongest during the boreal summer, when ACC is elongated from the Atlantic Ocean to the Ethiopian highlands. The second principal component, representative of the south-eastern and equatorial Atlantic, is also linked with the extension and the longitudinal position of the ACC (greatest extension/westernmost position when the equatorial and South Atlantic is anomously warm, and inversely). The intermonthly variability of the latitude seems more noisy and less related to the large-scale SST patterns than the other parameters.
\end{abstract}

KEY WORDS African convection centre Outgoing longwave radiation Sea-surface temperature Diagnostic approach

\section{INTRODUCTION}

The main convective centres, situated over the so-called 'Maritime Continent', the Amazon Basin, and the Congo Basin, are fundamental to the global climate owing to the convection and the associated release of latent heat (Hastenrath, 1988, 1990). These convective centres are viewed generally as ascending portions of the zonal circulation cells (Hastenrath, 1990). Before the 1970s, the functioning of the three main convective centres remained obscure owing to the lack of data. The development of satellites offered a promising approach for studying the variability of these centres. The outgoing longwave radiation (hereafter OLR), continuously monitored from June 1974 by the polar orbiting NOAA satellites, varies with the cloud top temperatures, and low values indicate the major convective systems, extending upward to the tropopause (Heddinghaus and Krueger, 1981). We have chosen a threshold of $235 \mathrm{~W} \mathrm{~m}^{-2}$ for delineating the main convective centre over tropical Africa. A lower threshold restricts the spatial definition of the convective centre and although monthly values of less than $230 \mathrm{~W} \mathrm{~m}^{-2}$ are recorded over the Congo basin, they are rare over West Africa. A higher threshold could introduce much confusion between convective clouds and other forms. The threshold of $235 \mathrm{~W} \mathrm{~m}^{-2}$ allows us to delineate a usually continuous area, even if this situation does not exist at smaller temporal scales than those we used here.

The variability of the African convective centre (hereafter ACC) is documented using the NOAA OLR data set from June 1974 to December 1991. Three main pararmeters are used to study the variability of ACC: spatial extension, position (computed by the centre of gravity), and intensity. The relationships between unfiltered and filtered series of the parameters of the ACC and the main SST modes are then documented. The first section describes the methods and the data. The second section presents the data

CCC 0889-8418/95/010025-10

(C) 1995 by the Royal Meteorological Society 
and the basic processings. The third part examines the variability (raw and standardized data) of ACC, even though the following section presents the relationships between the variability and the main SST modes. The fifth section discusses the results and the sixth concludes the paper.

\section{METHODS AND BASIC DATA PROCESSING}

The OLR data set is presented extensively in many diagnostic studies documenting the variability of OLR on global scales (Heddinghaus and Krueger, 1981; Short and Calahan, 1983; Chelliah and Arkin, 1992; Waliser et al., 1993). The data available for this study are obtained from the scanning radiometer aboard the polar orbiting NOAA satellites from June 1974 to December 1991 (with a gap from February to December 1978), with two samplings per day (Grueber and Krueger, 1984). These data were averaged monthly for $2 \cdot 5^{\circ}$-square areas. The main problems of this data set are the different equatorial crossing times and the window channel used, discussed in Short and Calahan (1982) and Gadgil et al. (1992). Chelliah and Arkin (1992) demonstrated clearly that the greatest part of the variability in tropical North Africa is related to the change in the equatorial crossing time. This instrmental bias seemed to be less important in equatorial Africa (see figure 3 of Chelliah and Arkin, 1992). The raw data were aggregated primarily in $5^{\circ}$-square areas and the main convective zone was delineated by grid-points with OLR less than $235 \mathrm{~W} \mathrm{~m}^{-2}$ between $17.5^{\circ} \mathrm{N}$ and $17.5^{\circ} \mathrm{S}$ and between $18^{\circ} \mathrm{W}$ and $46^{\circ} \mathrm{E}$. The grid-points with OLR less than $235 \mathrm{~W} \mathrm{~m}^{-2}$ but situated along the subtropical edges of the domain, and related to the cirriform bands elongated from equatorial to middle latitudes (Streten, 1973; Thepenier, 1983), were eliminated from this counting. This problem occurs during the winter of each hemisphere, and it is relatively easy to subjectively differentiate these cirriform clouds from the ACC, which is located in the summer hemisphere. Three parameters are defined. The extent of the ACC equals the number of grid-points with an OLR less than $235 \mathrm{~W} \mathrm{~m}^{-2}$. A correction using the cosine of the latitude to account for the different area represented by a sole grid-point appears not to be necessary owing to the low latitude involved. The position, latitude (north = positive values) and longitude (west = positive values), is determined by the centre of gravity of the area having an OLR less than $235 \mathrm{~W} \mathrm{~m}^{-2}$. The mean intensity of the ACC is then computed by the mean of the grid-points having an OLR $<235 \mathrm{~W} \mathrm{~m}^{-2}$.

The series are standardized monthly on the basis of the equatorial crossing hour. Then the standardized anomalies are computed separately for the period June 1974 to February 1978 (plus February 1980 to August 1981) with an equatorial crossing hour of 0730-0930 and 1930-2130 and for the remaining period (January 1979 to January 1980 and September 1981 to December 1991) with an equatorial crossing hour of $0230-0330$ and $1430-1530$. The total period was reconstituted after this step. A reverse low-pass filter, according to the recursive Butterworth method, was applied to the standardized series to remove the highest frequencies (= with period less than 12 months). A reverse filter is necessary so that the phase of the filtered series will not be altered (Raymond and Gardner, 1991). In the recursive approach the filtered quantities are functionally dependent upon all unfiltered values, and also upon all previously filtered values. The coefficients of the filter are commonly derived to satisfy an assigned response function. The strength of correlation is tested using the Der Megredichtian (1979) method, recently used by Fontaine and Janicot (1992) and Moron (1994) to account for the reduction of effective degrees of freedom in the time domain due to persistence. The low-pass filter, retaining the lowest frequency, induces a decrease in the effective degrees of freedom. The composites are tested using the Student's $t$-test.

Sea-surface temperatures (SST) were provided by the UK Meteorological office (Bottomley et al., 1990). The data are corrected from an instrumental bias (Folland and Parker, 1990), and are weighted by the sine of the latitude of the grid points in order to take into account spatial differences related to representation by a single grid-point.

\section{THE VARIABILITY OF THE AFRICAN CONVECTION CENTRE}

\subsection{Raw data}

Figure 1 displays the mean monthly maps of OLR computed from the total available period (June 1974 to December 1991). The latitudinal migration is nearly symmetric relative to the Equator, following 

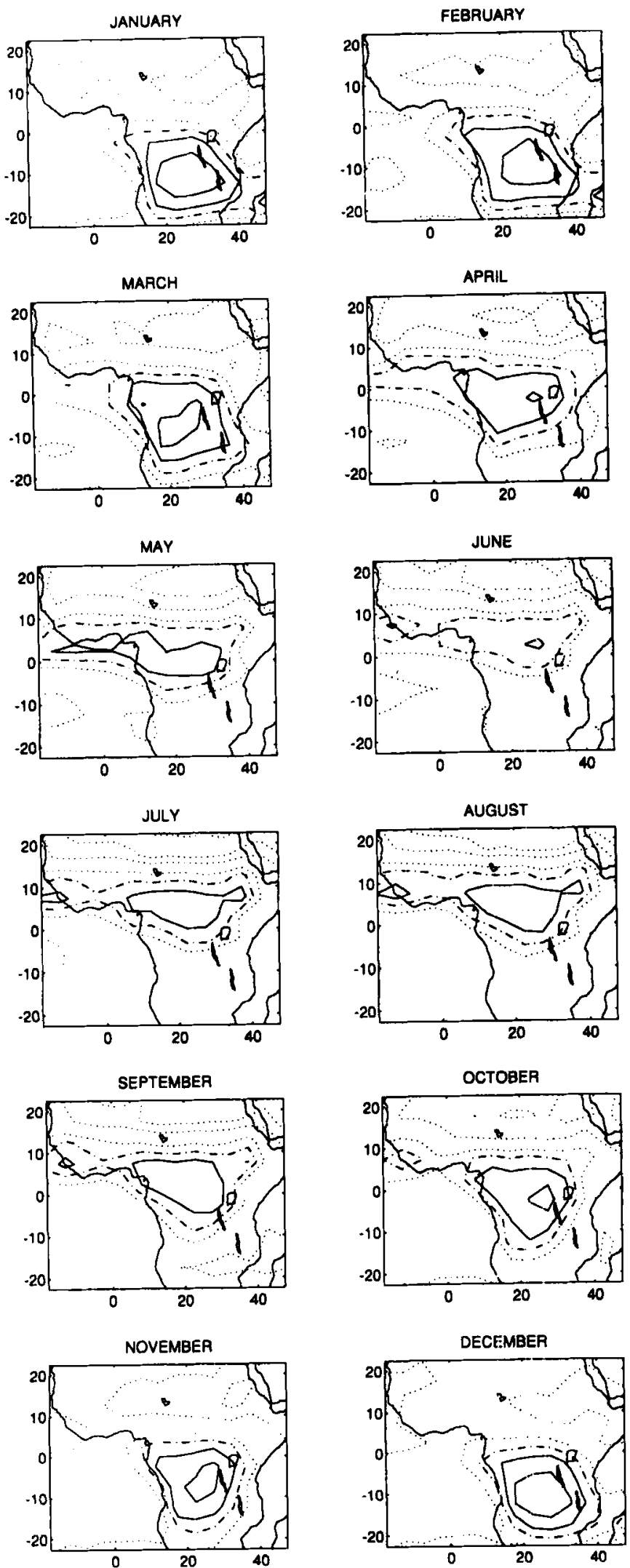

Figure 1. Maps of mean OLR from January to December. Means were computed from monthly averages from June 1974 to December 1991. Dashed-dotted line represents the $235 \mathrm{~W} \mathrm{~m}^{-2}$ delineating the African convection centre. Dotted lines are, respectively, 250, 265, and $280 \mathrm{~W} \mathrm{~m}^{-2}$. Full lines are 220 and $205 \mathrm{~W} \mathrm{~m}^{-2}$ 

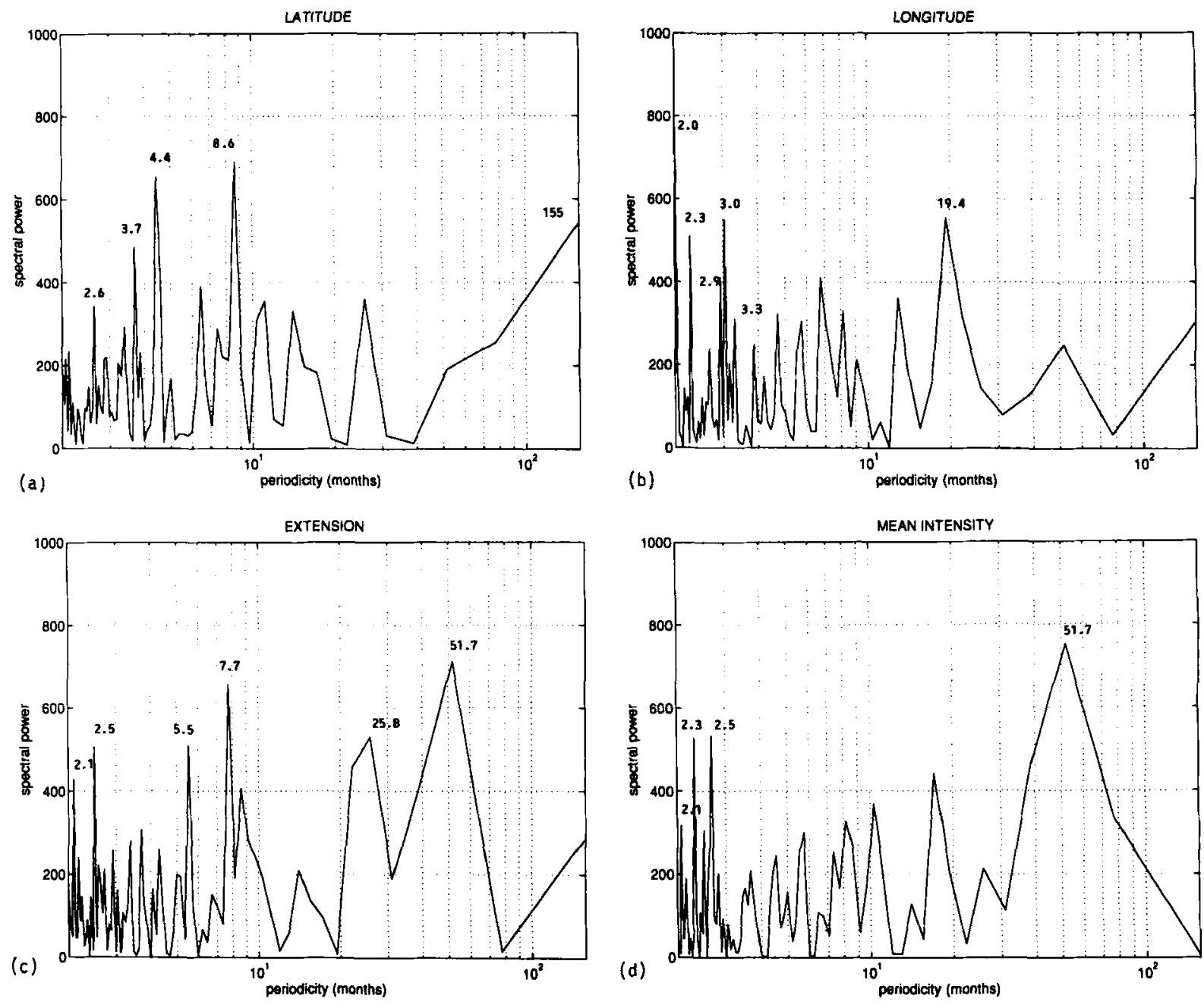

Figure 2. Power density of the normalized monthly time series for the latitude (a), longitude (b), extension (c), and mean intensity (d) of the ACC. The values are computed for the 1979-1991 period owing to a gap in the record in 1978. The significant periodicities (in months), assessed from a Monte Carlo simulation based on 1000 pseudo-random time series possessing the same serial correlations (order 1 ) and the same variance as the original values, are noted on the figure

the progression of the Sun (Waliser and Gautier, 1993). The northward migration (from March to June) is slower than the southward (from October to November). Also note that the ACC is quite broad and almost circular when it is positioned over the tropical South Africa during the austral summer (Figure 1), even though it is narrow and zonally elongated at its northernmost position (Figure 1). The mean intensity is strongest during the austral summer (December-February) and weakest during the end of the boreal spring (June). The mean intensity is significantly correlated with latitude $(r=0.69$, significant at the 0.01 level) and with longitude $(r=0.64$, significant at the 0.01 level). The two quasi-stationary stages, with a circular shape and the greatest annual mean intensity in December-February and with an elongated shape in JulySeptember, are separated by two propagating stages (a slow northward migration from March to June with decreasing mean intensity and a fast southward migration from October to November).

\subsection{Anomaly data}

The series are standardized monthly on the basis of the equatorial crossing hour (see section 2). The power density of the normalized time coefficients of the four parameters (Figure 2a-d) exhibits several peaks of the frequency bands that correspond to three main characteristics time-scales; (i) high-frequency 


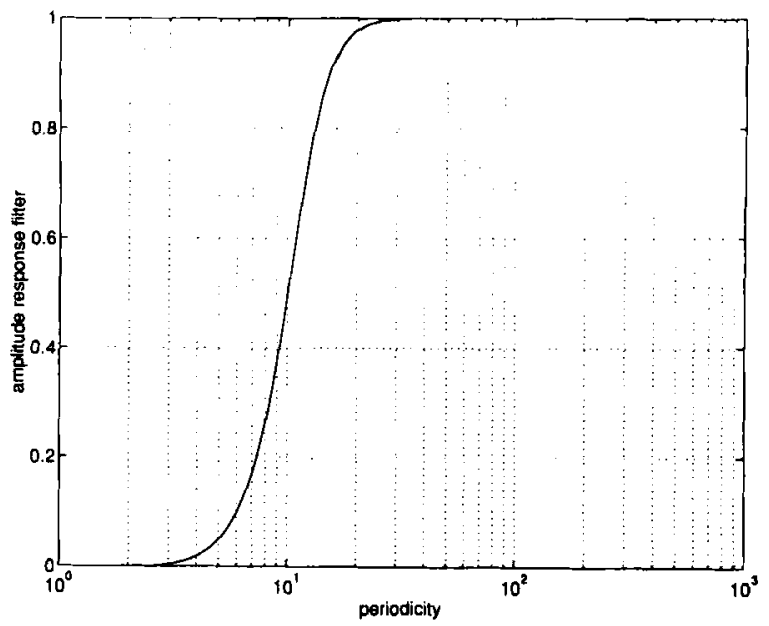

Figure 3. Amplitude response as a function of period for the recursive low-pass filter used in the analysis

(a)

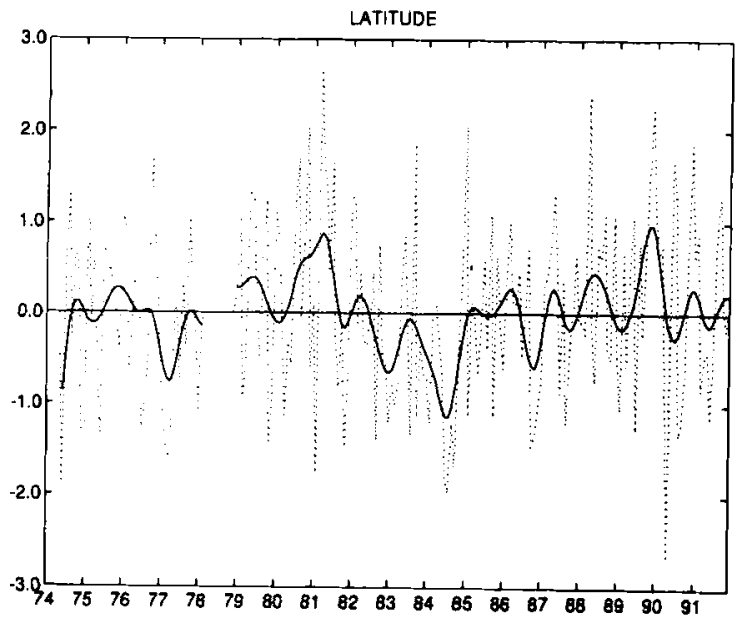

(c)

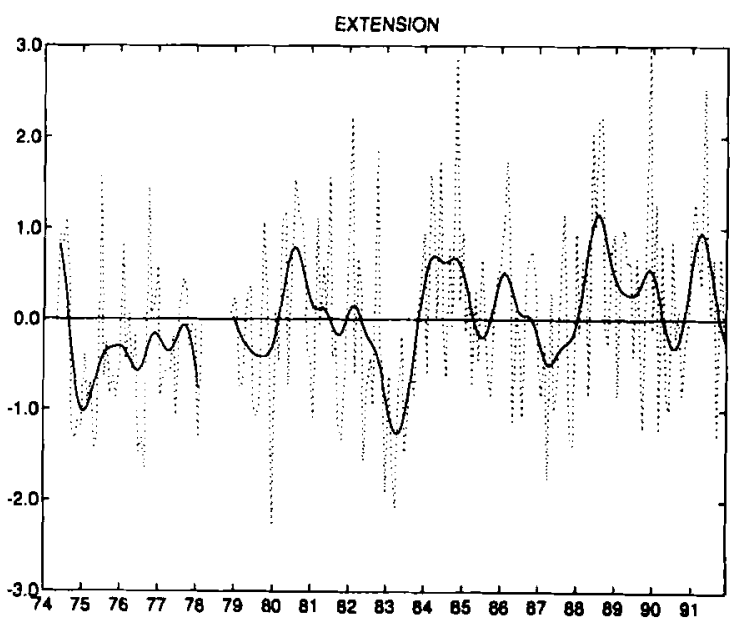

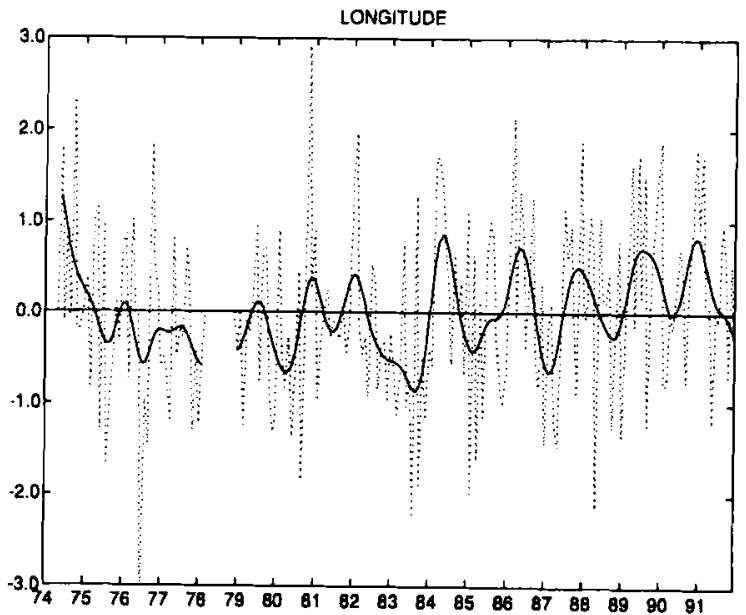

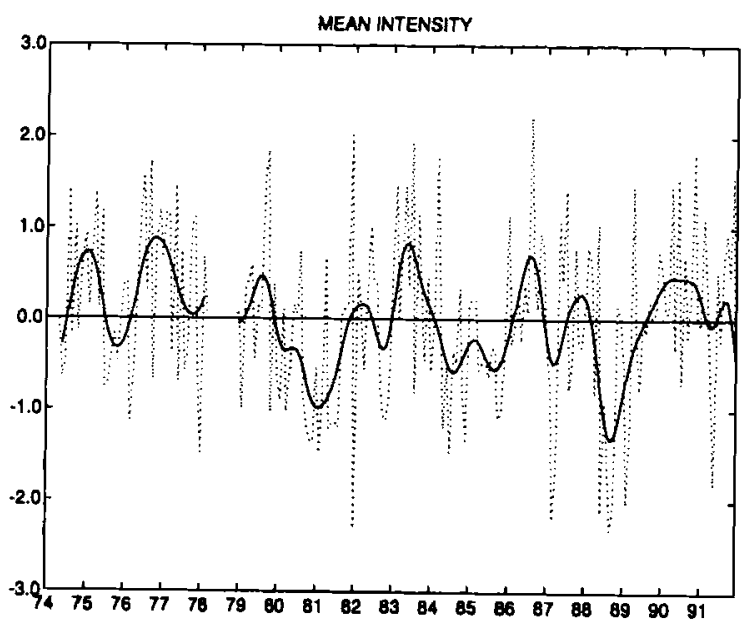

Figure 4. Monthly standardized values (unfiltered (dotted lines) and filtered (full lines) series, using a low-pass reverse Butteerworth filter) for latitude (a), longitude (b), extension (c), and mean intensity (d) of the African Convection Centre 
variability (between 2 and 6 months), indicating that homogeneous anomalies do not persist for a long time, is associated with the four parameters (Figure 2(a-d)); (ii) a median-frequency variability (between 6 and 15 months) is still present in the latitude and the extension of the ACC despite removing the annual cycle by normalization; (iii) a low-frequency variability (from 20 to 52 months) is also present, mainly for the intensity and the extension of the ACC (Figure 2(c and d)). The lowest frequencies represent the main climatic signal of interest here. Finally, a reverse low-pass filter (Figure 3), removing frequencies higher than one cycle per year, is applied to the monthly time series (see section 2).

The standardized series of latitude, presented in Figure 4(a) is noisy and the filtered series do not remain above or below the long-term mean for a very long time. The more remarkable southerly position occurs in the austral summers of 1977-1978 and 1982-1983, the boreal summer of 1984, and at the end of 1986. The more northerly position is attained from mid-1980 to mid-1981, the boreal spring of 1986 and 1987 , and the boreal summers of 1988 and 1989. The standardized series of longitude is also highly noisy (Figure 4(b)). The negative values, depicting an easternmost position, occurred at the beginning of 1980 , during 1983, and at the beginning of 1985 and 1987. The standardized series of the extension and the intensity of the ACC (presented in Figure 4(c and d)) are less noisy. The negative anomalies of mean intensity in fact depict increasing convection. The filtered mean intensity and extension present a correlation of -0.58 (significant at the 0.05 level), therefore, the extension and the convection are low in 1974-1976, 1979, 1982-1983, 1986, and 1990 even though the reverse pattern occurred mainly in 1980-1981, 1984, 1988, and 1991.

\section{RELATIONSHIPS BETWEEN ACC AND THE GLOBAL SCALE SST PATTERN}

Principal component analysis was carried out on monthly $5^{\circ}$-squares of SST for the period January 1974 to December 1990 on the covariance matrix. Seven principal components, representing $50 \cdot 2$ per cent of the total variance were rotated according to the 'scree-test' (O'Lenic and Livezey, 1988), using the Varimax criterion (Richman, 1986). The two first principal components, representing the most significant modes of variability, are displayed in Figure 5 . The first mode (18.3 per cent of the total variance) describes the variability of the eastern and central Pacific and the tropical Indian Ocean. The time evolution depicts well the 'El-Niño' warm events of 1976-1977, 1982-1983, 1986-1987 and 1990 and the 'La Niña' cold events of 1974-1975, 1978, 1981, 1984-1985 and 1988-1989. This mode is called 'tropical Pacific and Indian Ocean mode' (TPIm). The second pattern, called 'tropical South Atlantic mode' (TSAm), represents the variability of the southern and equatorial Atlantic Ocean (Figure 5) with a persistent time series (negative values before 1983 and positive values after this date, with the main warm events in 1984 and 1988). The warm event of 1984, following the Pacific ENSO of 1982-1983, has been studied extensively by Philander (1986) and Mechoso and Lyons (1989). Note also that the time series of the two modes are more persistent than the time series of the parameters of the ACC (Figures 3 and 5).

Correlations between the two SST modes and the filtered series of the parameters of the ACC are presented in Table I. The linear correlations between the parameters describing the ACC and the main SST modes are smaller when the series are unfiltered owing to the noise of the raw series (not shown). The statistical links are greater with TPIm than with TSAm. The sense of correlation indicates clearly that a warm anomaly on TPIm (= 'El Niño' conditions) is associated with a spatial contraction, a decreasing mean convection, and an eastern position of the ACC. The statistical links are inverse for TSAm, with a greater extension and a western position when anomalous warm conditions prevail on the southern and equatorial Atlantic. The relationships could be biased by the skewness of the distribution, and composite analysis provides a useful tool for completing the analysis.

The data were analysed for periods relative to the annual cycle of the ACC (December-February, March, April, May, June, July-September, October, November) and the seven warmest and coldest years for TPIm and TSAm were extracted (Table II). The related anomalies of parameters of ACC were then computed and tested. The results are presented in Tables III-IV. The composites reveal the same features as the linear correlations, even if the first are computed on an unfiltered series. The anomalous warm conditions for the TPIm are linked with a decreasing mean convection and extension of $A C C$, even though the reverse conditions are linked with an increasing mean convection and extension of ACC (Table III). A new feature 

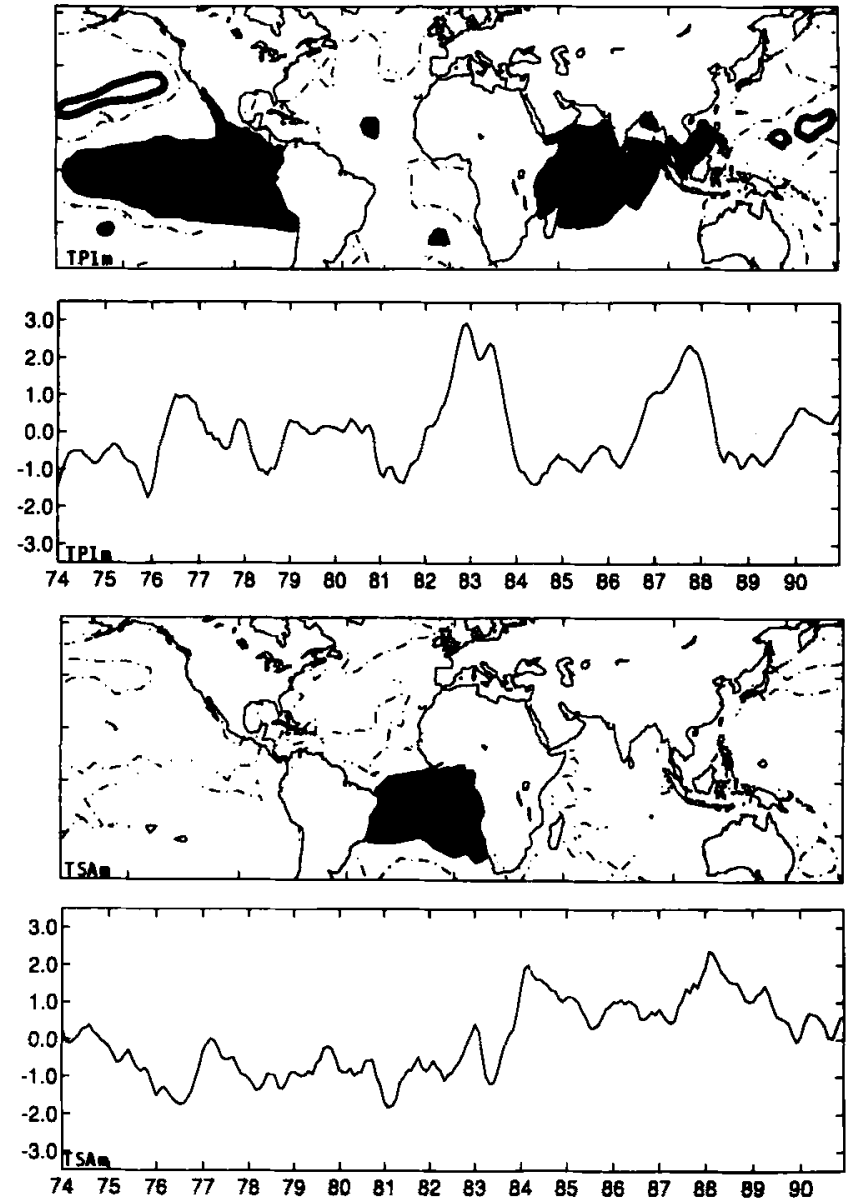

Figure 5. Loading patterns and normalized time series coefficients of the two first principal component computed from the covariance matrix of monthly sea-surface temperature (January 1974-December 1990). The area in black (surrounded by a black line) represents the positive (negative) loading patterns significant at the 0.05 level when the serial correlation of the prrincipal components is taken into account. The dashed-dotted line depicts the 0 value

with regard to correlations is that the anomalous conditions are usually strongest during the boreal summer. The anomalous conditions in the eastern and central Pacific usually originate during the boreal spring (March-April), and peak around the end of the calendar year. The links between the TPIm and longitude are less clear (Table III). An eastern position of the ACC occurs during the March-August period, when the TPIm is anomalously warm even though other differences are close to zero. The relationships with the latitude of $\mathrm{ACC}$ are not clear, as for the linear correlations (Table III). The composites related to extreme conditions for the TSAm also reveal the same features as correlations. In contrast to the TPIm, the

Table I. Correlations $(\times 100)$ between the TPIm and TSAm, and the parameters describing the African convection centre. A low-pass reverse filter (Butterworth method), removing frequencies higher than 0.08 cycles month $^{-1}$ (=1 cycle per 12 months) was applied before the computation of linear correlations

\begin{tabular}{lcccc}
\hline & Extension & Mean intensity & Longitude & Latitude \\
\hline TPIm & $-48^{*}$ & $42^{*}$ & $-34^{*}$ & -12 \\
TSAm & $49^{*}$ & -20 & $41^{*}$ & -27 \\
\hline
\end{tabular}

* Significant at the 0.1 level, taking into account the effective degrees of freedom. 
Table II. Ranking list, in descending order, of the seven coldest and warmest periods of the two first sea-surface temperature modes computed over the 1974-1990 period

\begin{tabular}{|c|c|c|c|c|}
\hline & TPIm cold & TPIm warm & TSAm cold & TSAm warm \\
\hline December- & 75818984857586 & $8388 \quad 87907780$ & $7678 \quad 8182758077$ & 88848786898590 \\
\hline March & 84818685897675 & 83878890798280 & 81767980827583 & 88848985869087 \\
\hline April & 84818685897576 & 83879088828077 & 81768379828075 & $\begin{array}{l}88848985869087\end{array}$ \\
\hline May & 84818685897588 & 83878290768079 & 76838182807975 & 88848985869087 \\
\hline June & 84818589758886 & 83878276908079 & 76838182798077 & 88848985869087 \\
\hline July-September & 84817585748889 & $\begin{array}{l}87838276908079\end{array}$ & 81767980827775 & 88848985878386 \\
\hline October & $\begin{array}{lllllll}75 & 74 & 84 & 81 & 88 & 85 & 89\end{array}$ & 82877683869080 & 76757780818279 & 87888489858690 \\
\hline November & 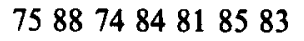 & 82878676907779 & 76807775817982 & 87848885869083 \\
\hline
\end{tabular}

Table III. Periods showing the standardized parameters characterizing the ACC between ensembles of seasons with extremely cold and extremely warm conditions in the TPIm (displayed in Table II). The difference between the two samples is tested using a $t$-test. For the extension and mean intensity, $a^{\prime}+{ }^{\prime}\left({ }^{\prime}+++{ }^{\prime}\right)$ denotes a positive (significant at the 0.1 level) anomaly (with mean intensity previously multiplied by -1 ), and inversely for ' - ' ( $-\ldots-$ ). For the latitude, a ' $n$ ' (' $N$ ') represents a northern (northern significant at the 0.1 level) position relative to the long-term mean and inversely for a ' $s$ ' (' $S$ '), which represents a southern (southern significant at the $0 \cdot 1$ level) position. For the longitude, a ' $w$ ' ('W') depicts a western (western significant at the 0.1 level) position relative to the long-term mean, and inversely for an ' $e$ ' ('E'), which represents an eastern (eastern significant at the 0.1 level) position

\begin{tabular}{lcccccccc}
\hline TPim & $12-2$ & 3 & 4 & 5 & 6 & $7-9$ & 10 & 11 \\
\hline INT - & + & + & - & + & +++ & +++ & - & + \\
INT + & - & + & + & - & --- & --- & + & - \\
EXT - & - & +++ & + & - & +++ & +++ & --- & - \\
EXT + & - & --- & - & - & --- & --- & +++ & - \\
LAT - & $\mathrm{s}$ & $\mathrm{n}$ & $\mathrm{n}$ & $\mathrm{n}$ & $\mathrm{s}$ & $\mathrm{n}$ & $\mathrm{s}$ & $\mathrm{s}$ \\
LAT + & $\mathrm{n}$ & $\mathrm{s}$ & $\mathrm{s}$ & $\mathrm{n}$ & $\mathrm{n}$ & $\mathrm{s}$ & $\mathrm{s}$ & $\mathrm{s}$ \\
LON & $\mathrm{e}$ & $\mathrm{w}$ & $\mathrm{W}$ & $\mathrm{w}$ & $\mathrm{w}$ & $\mathrm{w}$ & $\mathrm{w}$ & $\mathrm{e}$ \\
LON + & $\mathrm{w}$ & $\mathrm{e}$ & $\mathrm{E}$ & $\mathrm{e}$ & $\mathrm{e}$ & $\mathrm{e}$ & $\mathrm{e}$ & $\mathrm{e}$ \\
\hline
\end{tabular}

Table IV. As for Table III but for the seven coldest and warmest years of TSAm

\begin{tabular}{lcccccccc}
\hline TSAm & $12-2$ & 3 & 4 & 5 & 6 & $7-9$ & 10 & 11 \\
\hline INT - & + & + & - & - & - & + & + & + \\
INT + & + & + & - & + & + & + & + & - \\
EXT - & -- & -- & - & - & - & - & + & - \\
EXT + & +++ & +++ & + & - & + & + & - & + \\
LAT- & s & s & n & n & n & n & N & s \\
LAT + & n & n & n & s & n & s & S & n \\
LON & w & E & e & w & E & E & w & w \\
LON + & e & W & w & e & W & W & e & w \\
\hline
\end{tabular}

anomalous conditions are stronger during the first semester (Table IV). Therefore the westernmost/easternmost position of the ACC when the TSAm is anomalously warm/cold occurs mainly from March to August, when the ACC moves northward. The links between the TSAm and the extension of the ACC peak also during the first semester (Table IV).

\section{DISCUSSION}

This study seems to indicate that the extension and the mean convection of the ACC are associated mainly with the TPIm, even though the equatorial and South Atlantic SST patterns seem less important (Moron, 1993). Heddinghaus and Krueger (1981) and Chelliah and Arkin (1992) demonstrated that the first 
non-seasonal eigenvector of OLR is linked with ENSO events. They also indicated that the loading patterns associated with this eigenvector are close to zero over tropical Africa. Hastenrath (1990), using the 'Highly Reflective Cloud' (HRC) data set, taking into account only the diurnal convection, demonstrated clearly that the Southern Oscillation Index is correlated negatively with HRC over central Africa during most of the year. However, the correlations are usually not significant at the 0.05 level. The results presented here apparently differ from results found previously. However, these authors studied only the intensity of convection, and did not filter their data series. The low-pass reverse filter seems very important for revealing the apparent relationships between the TPIm and the variability of the ACC, because it removes the natural 'noise'. The composites indicate that the statistical link is unstable during the year with a greatest association with the boreal summer, when warm events in the eastern and central Pacific develop themselves and when the ACC extends from West Africa to the Ethiopian Highlands. The anomalous dry conditions recorded over Guinean and Sahelian Africa during the Pacific warm events from 1970 are in accordance with these results (Moron, 1994). Other diagnostic studies (Fontaine et al., 1994) or modelling studies (Palmer et al., 1992), not concerned directly with OLR data, indicate possible links between ENSO and climatic anomalies over tropical Africa. The warm events are susceptible to forcing a convergence anomaly in the high troposphere, inhibiting convective processes over West Africa. The present study seems to confirm this hypothesis more directly. If the ACC is viewed as the ascending branch of the African zonal circulation cell, the ENSO events are linked firstly with a decreasing intensity and extension of the ACC, and secondly with an eastern position of this cell. The relationships between the TPIm and the variability of the ACC during the austral summer are less clear. It could be argued that temporal covariation exists between the eastern and central Pacific and the tropical Indian Ocean, represented almost equally in the TPIm (Figure 5). Eventually a 'remote' effect connected with the warm events of the central and eastern Pacific could be mixed with a different 'local' effect provided by the warm SSTs in the Indian Ocean. The question of the interaction between 'remote' and 'local' effects of the SSTs on large-scale convection remains open (Zhang, 1993). We cannot form generalizations based on these results because the period is short and the ENSO events are particularly strong during this phase. The migration of the ACC seems more related to regional-scale conditions, although the results are less significant than for the extension/mean convection of the ACC.

\section{CONCLUSION}

The variability of the African convection centre is studied from OLR records (June 1974 to December 1991). The ACC is delineated by OLR values less than $235 \mathrm{~W} \mathrm{~m}^{-2}$ on a $5^{\circ}$-square grid. Four parameters (latitude, longitude, mean intensity, and extension) are analysed. The monthly normalized time series are dominated by high frequencies (from 2 to 12 months) even though a low variability (from 25 to 52 months) exists mainly for the mean intensity and the extension of the ACC. A reverse low-pass filter is applied to the series in order to remove the highest frequencies and to extract the climatic signal. The comparisons with the two first main modes of the global-scale SST indicates that the extension and the mean convection of the ACC are linked primarily with the TPIm, which integrates the well-known ENSO oscillation. The extension and the mean intensity are then unusually low, mainly from June to September, when 'El Niño' conditions prevail in the eastern and central tropical Pacific, suggesting a 'remote' effect of the eastern and central Pacific (and perhaps of the Indian Ocean) on the African convection. The relationship is globally inversed during ' $\mathrm{La}$ Niña' conditions, although the anomalies are smaller in the absolute sense. The regional conditions seem less important. The south-eastern and equatorial Atlantic, revealed by the second principal component, are linked with the longitude and the extension of the ACC (respectively westernmost/greatest when SST are warmer than normal, and inversely). The latitude is more noisy and less related to large-scale patterns of SST than other parameters.

\section{ACKNOWLEDGEMENTS}

I am very thankful to NOAA administration for providing OLR data and the UKMO (David Parker) for providing the SST data. Thanks are also due to the two anonymous reviewers, whose comments greatly improved the first version of this paper. 


\section{REFERENCES}

Bottomley, M., Folland, C. K., Hsiung, J., Newell, R. E., and Parker, D. E. 1990. Global Ocean Surface Temperatures (GOSTA), United Kingdom Meteorological Office, Bracknell, 20 pp. +313 plates.

Chelliah, M. and Arkin, P. 1992. 'Large-scale interannual variability of monthly outgoing longwave radiation anomalies over the global tropics', J. Climate, 5, 371-389.

Der Megredichtian, G. 1979. 'L'optimisation des réseaux d'observations des champs météorologiques', La météorologie, $V^{\circ}$ série, $51-66$.

Folland, C. K. and Parker, D. E. 1990. 'Observed variations of sea surface temperatures', Ocean Air Interact., 21-52.

Fontaine, B. and Janicot, S. 1992. 'Wind field coherence and its variation over West-Africa', J. Climate, 5, 512-524.

Fontaine, B., Janicot, S. and Moron, V. 1994. 'Monthly mean wind signal and rainfall anomaly patterns over northern Africa in August 1958-1989', submitted to J. Climate.

Gadgil, S., Guruprasad, A. and Srinivasan, J. 1992. 'Systematic bias in the NOAA outgoing longwave radiation dataset?' J. Climate, $5,867-875$.

Gruber, A. and Krueger, A. F. 1984. 'The status of NOAA outgoing longwave radiation data set', Bull. Am. Meteorol. Soc., 65, 958-962.

Hastenrath, S. 1988. Climate and Circulation of the Tropics, D. Reidel, Dordrecht, 455 pp.

Hastenrath, S. 1990. 'The relationship of highly reflective clouds to tropical climate anomalies', J. Climate, 3, 353-365.

Heddinghaus, T. R., and Krueger, A. F. 1981. 'Annual and interannual variations in outgoing longwave radiation over the tropics', Mon. Wea. Rev., 109, 1208-1218.

Mechoso, C. R. and Lyons, S. W. 1988. 'On the atmospheric responses to sea surface temperatures anomalies associated with Atlantic warm event during 1984 ', $J$. Climate, $1,422-428$.

Moron, V. 1993. 'Variabilité de la radiation OLR sur l'Afrique tropicale et relations avec la circulation de mousson ouest-Africaine et les SST de l'Atlantique et du Pacifique Est', Proceedings of the 8th 'Atelier de Modélisation', CNRM, Toulouse, pp. 327-336.

Moron, V. 1994. Guinean and Sahelian rainfall anomaly indices at annual and monthly scales (1933-1990) Int. J. Climatol., 14, 325-341.

Nitta, T. and Yamada, S. 1989. 'Recent warming of tropical surface temperature and its relationship with northern hemisphere circulation', J. Meteor. Soc. Japan, 67, 375-383.

O'Lenic, E. A. and Livezey, R. E., 1988. 'Practical considerations in the use of rotated principal components analysis in diagnostic studies of upper height fields', Mon. Wea. Rev., 116, 1682-1689.

Palmer, T. N., Brankovic, C., Viterbo, P. and Miller, M. J. 1992. 'Modelling interannual variations in summer monsoons', J. Climate, $5,399-417$.

Philander, S. G. H. 1986. 'Unusual conditions in the tropical Atlantic Ocean in 1984', Nature, 222, 236-238.

Raymond, W. H. and Garder, A. 1991. 'A review of recursive and implicit filters', Mon. Wea. Rev., 119, 477-495.

Richman, M. B. 1986. 'Rotation of principal component', J. Climatol., 6, 293-335.

Short, P. A. and Calahan, R. F. 1983. 'Interannual variability and climate noise in satellite observed OLR', Mon. Wea. Rev., 111, 572-577.

Streten, N. A. 1973. 'Some characteristics of satellite-observed bands of persistent cloudiness over the southern hemisphere', Mon. Wea. Rev., 101, 486-495.

Thepenier, R. M. 1983. Etudes des perturbations nuageuses de l'hémisphère nord: rôle de la convection dans la cyclognénèse, Thèse de doctorat, Paris, $181 \mathrm{pp}$.

Waliser, D. E. and Gautier, C. 1993. 'A satellite derived climatology of the ITCZ', J. Climate, 6, 2162-2173.

Waliser, D. E., Graham, N. E. and Gautier, C. 1993. 'Comparison of the highly reflective cloud and outgoing longwave radiation datasets for use on estimating tropical deep convection', J. Climate, 6, 331-353.

Zhang, C. 1993. 'Large-scale variability of atmospheric deep convection in relation to sea surface temperature in the tropics', $J$. Climate, 6, 1898-1913. 